Myers (instinct), Dr. W. H. Thorpe (learning processes in animals), Dr. F. B. Kirkman (bird behaviour), Prof. D. B. Johnstone-Wallace (grazing habits of beef cattle), and Dr. Arthur Walton (comparative sexual behaviour in the male). It was agreed also that Prof. Samson Wright and other psychiatrists should be invited to speak at this or a succeeding meeting. Future research projects were discussed, especially those in the veterinary field; for example, the individual behaviour of various domestic species, the grazing habits of sheep and cattle, and the utilization of behaviour reactions in supplementing clinical, pathological and biochemical studies of domestic mammals. Certain ornithological studies, suitable for members, were also discussed. It was decided to circulate these projects at an early date. Consideration was given to the matter of research grants, and it was agreed to take steps to try to secure funds for specific observational studies involving domestic animals. Membership of the Institute is open to all interested persons. The annual subscription (12s. 6d.) includes payment for the Bulletin of Animal Behaviour. Communications should be addressed to the Hon. Secretary, Institute for the Study of Animal Behaviour, c/o Zoological Society of London, Regent's Park, N.W.8.

\section{The War-time Social Survey}

A PAPER on the "War-time Social Survey" was read at a meeting of the Royal Statistical Society on May 16 by Kathleen Box and Geoffrey Thomas. The War-time Social Survey is the Government social research unit, and has been set up to provide any department with information, needed for the planning and administration of policy, which is not available from other sources. It is concerned with social problems, in the investigation of which it aims at establishing facts and attitudes of the public towards these facts. The method used to achieve these ends may be described briefly as interviewing samples of the general public, or of particular sections of the general public, with a recording schedule devised so that the results of the inquiries made can be expressed statistically. Investigations are carried out by fiftyfive trained fieldworkers, all women. The reception accorded to fieldworkers suggests that the public is ready to appreciate the importance of such inquiries and to give all possible help. The proportion of people eventually refusing to be interviewed is about 0.5 per cent in most inquiries. The Survey has had to rely very largely on devising its own techniques for different occasions as they arose. The experience gained by other workers in the field of social research, both in Great Britain and in the United States, has been used, and most members of the research staff, coming as they do from different organizations which have been doing allied work for many years, have had different contributions to make.

The Survey can provide a closer link between the administrator and administered than is normally possible, particularly in relation to the preparation and interpretation of departmental statistics. In each Department of State there has been a large amount of unco-ordinated statistics related to very limited aspects of the department's work. By the extension of the survey method such obstacles can be overcome. Thus the data which it is most convenient for a department to obtain by a return can be supplemented in many ways by sample inquiries and thus assist in making decisions of policy. In this way a most flexible instrument for the compilation of a wide range of statistics can be developed. At the same time each department can remain in close touch with the collection of data, since the Survey normally discusses an inquiry in great detail with the officers concerned before it goes into the field. The experience of the Survey has shown during the past two years that its work has satisfied a real need for a specialist body able to advise on aspects of social inquiry which go beyond the official return, and there is little reason to suppose that this need will disappear when the War comes to an end.

\section{Illuminating Engineering Society}

THE annual report for the past year of the Illuminating Engineering Society, presented at the annual meeting held on May 9, directs attention to the formation of new centres in Bath and Bristol, and new groups in Derby, Huddersfield and Stocktonon-Tees. The Society is now organizing its activities. through seven distinct areas, each with its own committee which in turn is represented on the areas joint committee. 243 new members have been added to the Society during the past year; the number of meetings held, upwards of sixty, exceeds that in pre-war days. Recent educational efforts include the organization of essay competitions for pupils in schools near Birmingham, and the giving of a series of Christmas lectures on "The Wonders of Lighting" to more than a thousand children in Bradford. The Society has been instrumental in forming a joint committee, with which leading physiologists are associated, to deal with the physiology of vision, and has completed, for the Ministry of War Transport, a special investigation into the brightness and legibility of traffic signs. Three of the series of illustrated lighting reconstruction pamphlets, dealing respectively with "Principles of Good Lighting", "The Lighting of Schools" and "The Lighting of Public Buildings" have recently been issued. The following officers have been elected for the present session : President, Mr. E. Stroud ; Hon. Treasurer, Mr. N. V. Everton; Hon. Secretary, Mr. J. S. Dow.

\section{Early Medical Books at Edinburgh}

To illustrate a current series of lectures by Dr. Douglas Guthrie on "The Historical Background to Modern Medicine", there has been placed on view a collection of early printed medical books in the Upper Library Hall of the University of Edinburgh. Founded in 1580 as a "Town's Library" three years before the foundation of the University, or "Town's College", the University Library remained the only public library in Edinburgh until the establishment of the Advocates' Library a hundred years later. Naturally it contains many treasures, including a number of works of medical interest from which the present selection has been made. The most important and valuable items in the exhibition are Vesalius's "De Corporis Humani Fabrica" and Harvey's "De Motu Cordis". The beautifully bound copy of the former is the first edition, from the press of Oporinus of Basel, 1543. Beside it lies the fine two-volume edition, printed at Leyden in 1725 by Boerhaave and Albinus. The first edition of Harvey's account of the circulation of the blood is now an extremely rare little book, dated from Frankfurt, 1628. Visitors to the exhibition will have the opportunity of seeing two perfect copies, one of which belonged to Alexander Monro, the third of the dynasty of professors 
of anatomy of that name. The first Alexander Monro, when appointed to the chair in 1720, kept a list of his students which is now shown, as also is a printed copy of the first thesis to be presented for the degree of M.D., Edinburgh. It is entitled "De Dolore", by John Monteith, and the date is 1726. Later works on view are the second edition (1800) of Edward Jenner's "Inquiry into the causes and effects of variolae vaccinae", the first British edition of Beaumont's "Experiments and Observations on the gastric juice, etc." (1838), Morton's "Remarks on the mode of administering ether" (1847), and J. Y. Simpson's "Account of a new anaesthetic agent" (chloroform) (1847). Another landmark of medical literature is Lister's "Introductory Lecture", delivered in 1869 when he succeeded James Syme in the chair of clinical surgery at Edinburgh, and with it may be seen a manuscript set of notes of Lister's lectures, in the writing of one of his most distinguished students and successors, Prof. Caird. A feature of the exhibition, and the most spectacular item, is a fine collection of illustrated herbals, including a magnificent copy of "De Historia Stirpium", by Leonard Fuchs, dated 1542, with coloured wood-cuts, and a catalogue of the Physic Garden of Edinburgh (1683), by the first professor of botany, James Sutherland. The exhibition, which has been arranged through the kindness of Dr. L. W. Sharp and the Library Committee of the University, will remain open until June 3 .

\section{Rhinology and Folk-Lore}

IN a recent paper ( $J$. Laryng. and Otol., 57, 272 ; 1943) on this subject, Dr. J. D. Rolleston remarks that in contrast with the dearth of popular synonyms for the ear and larynx, the nose enjoys an abundance of such terms, which he suggests is mainly due to the prominent position which the nose occupies in the face. Another explanation of these numerous synonyms is the connexion of a large red nose with chronic alcoholism, though such a connexion has been greatly exaggerated. One of the earliest beliefs connected with the nose is that it is the portal of entry of the life or the soul, as is seen from the wellknown passage in Genesis relating to Adam. On the other hand, according to Sir James Frazer, the nose has been regarded by several savage races as the path by which life leaves the body. A popular belief in a close relationship between the size of the nose and the sexual organs in both sexes dates back to ancient times, and seemed at first to be confirmed at the end of the last century by the work of Fliess and others, who under the title of 'reflex neurosis' recorded a number of cases of uterine disease which had been cured by treatment of abnormal conditions of the nose. It now appears that the supposed connexion between the two organs in both sexes has been greatly exaggerated.

The folk-lore connected with sneezing is extremely abundant and dates back to remote ages, as is exemplified by many passages in the Bible, Homer, the Greek anthology, Xenophon and Petronius Arbiter. In accordance with the general rule in medical folklore, preventive measures are remarkably scanty in the case of rhinology and are chiefly employed in the management of epistaxis ; whereas therapeutic measures are extremely numerous and can be classified under the headings of remedies of human origin, animal remedies, plant remedies, mineral cures, hydrotherapy, charms, patron saints and miscellaneous cures.

\section{William Bartram of Philadelphia : Naturalist and Traveller}

THE son of John Bartram, botanist to His Majesty for the Floridas, William Bartram (1739-1823) shared his father's interest in Nature, and in 1773-74 carried out an extensive survey in Georgia and Florida. The results of his "Travels" he communicated in two manuscript volumes to his patron, Dr. John Fothergill, an Edinburgh medical graduate who had settled, and made a fortune, in London. After the death of Fothergill, the manuscripts came into the possession of Sir Joseph Banks, and they are now in the library of the British Museum (Natural History). Through the generosity of the American Philosophical Society and the John Bartram Association, this interesting record, thoroughly annotated by Francis Harper, has just been published (Trans. Amer. Phil. Soc., N.S., 33, 121 ; Nov. 1943). It gives a picture of the primeval wilderness of the south-east of North America, of the beauties of scenery and the wonders of plants and animals, of the Creek, Cherokee and Seminole Indians, until then largely unspoilt by the 'civilization' of white men. It is true that many of the wonders described by Bartram were regarded with scepticism in later years by those whose authority gave them some claim to pronounce judgment ; but it is one of the gratifying features of the investigations of Mr. Harper, who followed the Bartram trails over some ten thousand miles, that the authorities have been confounded and Bartram's accuracy vindicated, even in the much-disputed matters of the painted vulture of Florida and the bellowings of the alligators of St. John's, Florida, so circumstantially figured in the traveller's drawing, reproduced as Plate xiv in this paper.

\section{Railway Signalling on London Transport}

According to a paper read recently in London by R. Dell before the Institution of Electrical Engineers, the power-signalling installation on the railways of the London Passenger Transport Board now covers 160 miles of double track. There are 3,281 stop signals, 2,726 of which are fitted with trainstops. Track circuits number 4,347 and there are 1,326 pairs of points. Although automatic signals are used wherever possible, 112 signal cabins are in use at junctions or connexions in the track layout. The passenger-train car-miles run each year total approximately $159,150,000$. Power signalling has been in use practically throughout the system since it was electrified. The electrification of the District Line and the installation of power signalling commenced in 1904 and was completed by the end of 1905. The London Electric Tube Lines were equipped with power signalling from the start-the Bakerloo and the Piccadilly Lines in 1906 and the Hampstead Line in 1907. The Central London Railway was converted to power signalling in 1913 and the City and South London Railway in 1919. Except for these last two installations, the whole of the signalling system was originally operated on D.c. and track circuits were of the D.c. type with polarized relays in order to avoid improper operation by stray current from the traction system.

In the original installation the signals were all electro-pneumatically operated, with a moving spectacle in front of a fixed light for the tunnels and with semaphore arms in the open. All signals for passenger movements were provided with automatic trainstops. Although they gave remarkably satis- 